\title{
Oxygen consumption in the mullet Liza macrolepis with special reference to swimming velocity
}

\author{
M. N. KUTTY \\ Central Marine Fisheries Research Institute; Mandapam Camp, India \\ and \\ Department of Biological Sciences, Madurai University; Madurai, India
}

\begin{abstract}
Oxygen consumption of tagged (plastic opercular tag) and untagged mullet Liza macrolepis (SMITH), forced to swim up to $22 \mathrm{~cm} / \mathrm{sec}$ (fish size: $10 \mathrm{~cm}$ ), increased proportionately to increase in swimming velocity above $5 \mathrm{~cm} / \mathrm{sec}$. The tag did not appear to cause any marked metabolic disturbance. The mean routine metabolic rate and the rate at $5 \mathrm{~cm} / \mathrm{sec}$ were higher than the rates obtained for several higher levels of forced activity, possibly due to excitement and inefficient swimming at lower swimming speeds, as suggested by earlier workers. The interpretation of the elevation of a line drawn through the mean rates of metabolism at various swimming speeds, in relation to the standard metabolic rate, may be of value in quantitative expression of excitability of individual species.
\end{abstract}

\section{Introduction}

Oxygen consumption in relation to swimming speed in fishes has been studied by various workers (BRETT, 1964; BrEtT and SuTHERLAND, 1965; WoHlschlag, 1957, 1962; SMIr, 1965; MuIR et al., 1965; KUTTY, 1968). The present investigation mainly provides information on the energetics of swimming of an Indian mullet, Liza macrolepis (Sмттн) as judged from its oxygen consumption. A few experiments on tagged fish are also included in this study. It appears that there is no earlier report on the comparison of oxygen consumption of tagged and untagged fish, even though it has been reported that tagged fish are handicapped in their swimming abilities (CratroY, 1963).

Some determinations of the oxygen consumption of Liza macrolepis under spontaneous activity included in this investigation, may also be of interest in view of the paucity of information on the metabolism of tropical fishes (BEAMISH and DICKTE, 1966; WorrSOHLAG and CAMERON, 1967).

\section{Material and method}

Specimens of the mullet Liza macrolepis, about $10 \mathrm{~cm}$ long, were caught from Pullamadam creek which opens into Palk Bay, near Mandapam, (India). The fish were kept in a large tank in running water for acclimation. Within about 3 days after collection, the salinity of the water in the acclimation tank was gradually decreased to that of tap water, in which the fish were maintained for over 2 weeks before use in experiments. 'The tap water available in the Central Marine Fisheries Research Institute laboratories had a salinity of 0.3 to $0.5^{\circ} \%$ (see also JoB, 1957). The temperature of acclimation was $29^{\circ} \pm 1{ }^{\circ} \mathrm{C}$; the dissolved oxygen concentration was close to the level of air saturation.
The experiments were also performed in tap water at $29^{\circ} \mathrm{C}$. The ambient oxygen concentration during the tests was never below $60 \%$ air saturation. In most of the experiments the fish were forced to swim at known velocities. In a few experiments, routine metabolic rates of the fish were measured (Jos, 1955; KUTrY, 1967).

\section{Experimental procedure \\ Experiments under conditions of forced activity}

Experiments were performed using FRY's annular respirometer (FRY and HART, 1948; FRY, 1957), which can be rotated at desired speeds by a geared motor. The respirometer is made of transparent plastic, the outer diameter, the inner diameter and the height of the swimming channel (annulus) being $15.0 \mathrm{~cm}$, $5.5 \mathrm{~cm}$ and $9.5 \mathrm{~cm}$, respectively. The chamber has a volume of about $1,500 \mathrm{ml}$ and can be covered with a transparent plastic (hard) lid.

All fish used in this study were starved for $36 \mathrm{~h}$ before the experiments (BEAMISH, 1964). Each fish was transferred from the acclimation tank to the respirometer at least $12 \mathrm{~h}$ before the experiment, and kept in running water overnight.

Each exercise lasted $2^{1 / 2} \mathrm{~h}$ (excluding the flushing and sampling intervals); but metabolic rates were measured only during the last hour of the exercise. No measurements were taken during the initial $11 / 2 \mathrm{~h}$ in order to obtain, as far as possible, the steady metabolic (forced long-term) rate of the fish swimming at a specific speed (KuTrY, 1968). However, the rotation of the respirometer had to be stopped for about 2 min at intervals of 30 to $45 \mathrm{~min}$ to allow water sampling and flushing. This may have disturbed the fish, but perhaps not significantly enough to influence the results, as discussed later.

The protocol of an individual experiment was as follows:

The water supply to the respirometer was cut off and the exercise begun by starting the motor to rotate the chamber at a predetermined speed. The motor was stopped after $45 \mathrm{~min}$. Half of the water in the respirometer was quickly drained and the respirometer then filled up and flushed for $1 \mathrm{~min}$. The motor was restarted to rotate at the speed initially set. The rotation of the chamber was stopped again, as before, at the $90 \mathrm{th}$, 120th and 150th min, with the difference that water samples were taken from the respirometer during the last 3 stops, to enable determination of 
metabolism for the last 2 half-hour periods of the exercise. The first determination was made from the initial water sample taken subsequent to the flushing period at the $90 \mathrm{th} \mathrm{min}$, and the second sample taken immediately after the rotation of the respirometer was stopped at the 120th min. The second determination was made from the third water sample taken subsequent to the flushing at the $120 \mathrm{th} \mathrm{min}$, and the last sample taken immediately after stopping the respirometer at the 150 th min.

The fish were exercised at moderate speeds (up to about 2 body lengths/sec) at which they could swim for long periods (BarNBRDGE, 1961; BRETT, 1965). In each experiment the test individual was watched to check whether it maintained the speed at which the chamber was rotated. If the fish swam faster or slower than the speed of rotation, the laps gained or lost during the measurement of metabolism were taken into account when estimating the speed at which the fish was actually swimming. The speed of swimming was estimated assuming that the fish passed through a distance equal to the mean circumference of the annular swimming channel $(33 \mathrm{~cm})$ every time the chamber rotated once, subject to the correction.

\section{Experiments with tagged fish}

Experiments on tagged and untagged fish were performed concurrently. The fish was tagged with a plastic opercular tag. The average weight of 10 such

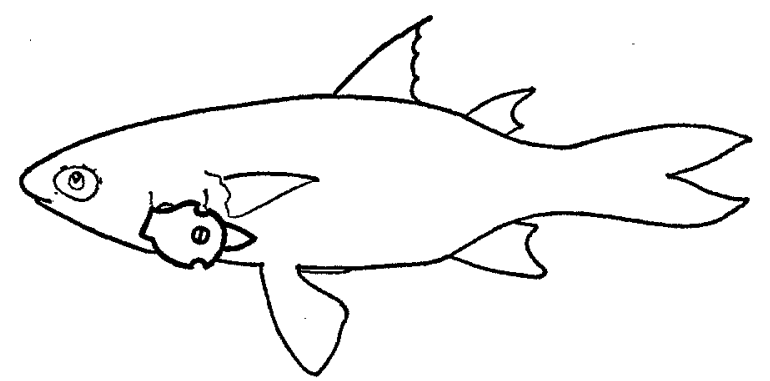

Fig. 1. Line drawing of tagged mullet Liza macrolepis

tags was $41.5 \pm 3.3 \mathrm{mg}$ (mean \pm S.D.). The fish was anaesthetised, using chlorobutanol (DURve, 1967), and the tag inserted through a narrow vertical slit. made at the junction of the preopercle and opercle of the fish (Fig. 1 gives a line drawing of the mullet with the tag in position). The fish was used in experiments $24 \mathrm{~h}$ after its recovery from anaesthesia.

\section{Experiments on routine metabolism}

Individual fish were transferred from the acclimation tank to a 11 flat-bottomed flask which served as a respirometer. During the subsequent 5 to $7 \mathrm{~h}$, the metabolic rate of each fish was estimated from the reduction of ambient oxygen in the respirometer in $20 \mathrm{~min}$ runs (closure periods) once an hour. Water in the respirometer and a 61 reservoir was kept circulated from one to the other during the flushing periods by means of a simple bent-tube siphon and an air-lift.

\section{Analysis of dissolved oxygen}

The unmodified Winkler method was followed for analysis of dissolved oxygen. For each sample collected $(60 \mathrm{ml}), 2$ or 3 separate titrations were made, and the mean of 2 near values taken as the oxygen concentration.

\section{Results}

A summary of the results of the experiments with untagged mullets are presented in Table 1 . The rate of

Table 1. Oxygen consumption in relation to swimming velocity in untagged Liza macrolepis, acclimated to, and tested in, fresh water at $29^{\circ} \mathrm{C}$. Experiments were performed on 5 different fishes (mean T.L. $=10.5 \mathrm{~cm} ;$ mean weight $=8.3 \mathrm{~g}$ )

\begin{tabular}{lll}
\hline $\begin{array}{l}\text { Swimming velocity } \\
\text { (cm/sec) } \\
\text { (Mean } \pm \text { S.E.) }\end{array}$ & $\begin{array}{l}\text { Oxygen consumption } \\
\text { (mg. kg. h) } \\
\text { (Mean } \pm \text { S.E.) }\end{array}$ & $\begin{array}{l}\text { Number of } \\
\text { determinations }\end{array}$ \\
\hline $4.7 \pm 0.15$ & $338 \pm 47$ & 5 \\
$10.1 \pm 0.22$ & $237 \pm 37$ & 16 \\
$13.9 \pm 0.11$ & $282 \pm 35$ & 9 \\
$16.7 \pm 0.39$ & $260 \pm 70$ & 6 \\
$18.8 \pm 0.02$ & $343 \pm 48$ & 7 \\
$22.4 \pm 0.66$ & $368 \pm 95$ & 3 \\
\hline
\end{tabular}

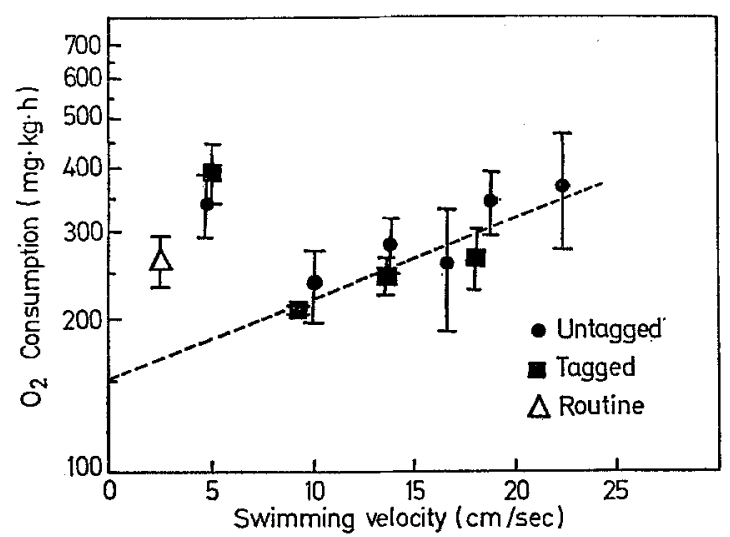

Fig. 2. Oxygen consumption in relation to swimming velocity in tagged (plastic opercular tag) and untagged Liza macrolepis (total length of fish used: $10.3-11.2 \mathrm{~cm}$ ) acclimated to, and tested in, fresh water at $29^{\circ} \mathrm{C}$. In all cases, metabolic rates indicate steady rates determined $11 / 2 \mathrm{~h}$ after the initiation of exercise in FRY's respirometer. The activity for routine rate is arbitrary. Vertical bars through points indicate standard error of the mean. The broken line shown in the figure is fitted by eye

oxygen consumption is plotted against swimming speed in Fig. 2 (circles). Except for the metabolic rate at the lowest swimming velocity $(5 \mathrm{~cm} / \mathrm{sec})$, the oxygen consumption increases with increase in swimming velocity, as indicated by the broken trend line drawn through values plotted in the figure.

Results of experiments with tagged fish are summarised in Table 2 and included in Fig. 2 (squares). Here again, the trend and the level of metabolism at different swimming speeds are similar to those for the untagged fish. It is noteworthy that here, also, the 
metabolic rate relating to the lowest swimming velocity stands higher and apart from the rest of the data plotted.

Routine metabolic rates of Liza macrolepis (mean T.L. $=8.2 \mathrm{~cm} ;$ S.D. $=1.34 ;$ mean weight $=5.6 \mathrm{~g}$; S.D. $=2.54 ; \mathrm{N}=4$ ) ranged between 85 and $551 \mathrm{mg}$. g.h (mean \pm S.E. $=262 \pm 29$ mg.kg.h; $\mathrm{N}=22$ ). The mean routine rate is also represented in Fig. 2 , arbitrarily at a swimming velocity of $2.5 \mathrm{~cm} / \mathrm{sec}$.

Table 2. Oxygen consumption in relation to swimming velocity in tagged (plastic operezdar tag) Liza macrolepis, acclimated to, and tested in, fresh water at $29^{\circ} \mathrm{O}$. Tests were made on a single fish only (total lergth $=10.8 \mathrm{~cm}$; weight $=8.5 \mathrm{~g}$ )

\begin{tabular}{lll}
\hline $\begin{array}{l}\text { Swimming velocity } \\
\text { (cm/sec) } \\
\text { (Mean } \pm \text { S.E.) }\end{array}$ & $\begin{array}{l}\text { Oxygen consumption } \\
\text { (mg. kg. h) } \\
\text { (Mean } \pm \text { S.E.) }\end{array}$ & $\begin{array}{l}\text { Number of } \\
\text { determinations }\end{array}$ \\
\hline $5.1 \pm 0.25$ & $392 \pm 53$ & 7 \\
$9.4 \pm 0.07$ & $219 \pm 3$ & 3 \\
$13.7 \pm 0.55$ & $248 \pm 21$ & 7 \\
$18.1 \pm 0.46$ & $266 \pm 35$ & 4 \\
\hline
\end{tabular}

Discussion and conclusion

The results presented suggest that there is no significant difference between the available values of oxygen consumption of tagged and untagged mullet. Even though no similar experiments have been reported earlier, ALverson and Chenoweth (1951) showed, experimentally, that Petersen disc tags and opercular strap tags on frozen albacore, when tested in a water tunnel, were ripped off within a few minutes. The velocities of the tuna tests were much higher than those of the present series, but it appears that the tuna tested were also much larger. In relative units (body lengths/sec) the speeds tested in the mullet are invariably higher. It appears that no reliable comparison can be made between the 2 series of tests, for it is also known that the energeties of 'swimming' and the manoeuverability of a live fish and a nonoscillating, dead fish may be markedly different (BRETT, 1963).

Clarcy (1963) found that steolhead trout tagged with Petersen disc tags were not able to swim as well as the untagged ones. CravoY also noted that tag looseness in the case of Petersen tags adversely affected performance. It is possible that the plastic opercular tags used, being light and staying almost within the contours of the fish, exert little extra drag on the fish. As pointed out in the 'experimental procedure' even though an attempt was made to obtain steady metabolic rates at the various velocities, this may not have been fully successful. Nevertheless, there is a tendency for a steady increase in oxygen consumption with increasing swimming velocity (Fig. 2). Therefore, it is likely that any error due to the experimental method adopted may not be significant. Considering the physiological aspects dealt with in this study, the plastic opercular tag does not appear to have any serious operative handicap.
A noteworthy feature in the results summarised in Fig. 2 is that several of the routine metabolic rates determined for the mullet are as high as, or higher than, the rates estimated for forced swimming (BRETT, 1964; SMIT, 1965; KUTTX, 1968). The mean rates for the lowest effort $(5 \mathrm{~cm} / \mathrm{sec})$ in the case of both tagged and untagged fish, are higher than the mean routine rate, which again is in agreement with observations of earlier workers on goldfish.

BRETr (1964) and SMIT (1965) observed that, with lesser swimming efforts, fish swim much less efficiently and, at these levels of activity, metabolic rates can be high due to the intermittent nature of swimming and increased excitement. At higher speeds, when swimming becomes more directed and efficient, oxygen consumption steadily increases with increase in effort; this is also evident from the present study. Even though steady ('forced long term') rates of oxygen consumption are considered, here it is observed, as in the cases of goldfish and rainbow trout (KUTTY, 1968), that there is a wide variation in the values obtained at the different swimming efforts tested. One may expect that the variation of the values will be less at still higher swimming speeds of the mullet, as has been found earlier in other fishes. Relatively, the highest swimming effort ( 2 body lengths/sec) tested in the present study, is only about half that of earlier studies (KUTTY, 1968).

Disregarding the values at $5 \mathrm{~cm} / \mathrm{sec}$, a line drawn through the mean metabolic rates at higher swimming velocities is seen to cut the $y$-axis at about $150 \mathrm{mg} . \mathrm{kg} . \mathrm{h}$ (broken line in Fig. 2). This value appears to be higher than the standard metabolic rate of the test fish. Earlier work has shown that the metabolic rate of a fish swimming at a given speed remains high during the initiation of the exercise, and decreases to a steady level with increase of the duration of the exercise. Thus, the lowest possible metabolic rate for a single level of activity could be obtained if the exercise is prolonged for a sufficiently long period. In a plot of the metabolic rates against the swimming speeds employed, a line drawn through the lowest rates obtained can be expected to cut the $y$-axis close to the standard metabolic rate (BRETT, 1964; SMIT, 1965; KUTTY, 1968).

In the present study, such a line (not shown in Fig. 2) through the lowest rates extrapolated to ' $O$ ' swimming speed, indicates a standard rate of about $50 \mathrm{mg} . \mathrm{kg} . \mathrm{h}$. The lowest routine rate obtained is $85 \mathrm{mg} . \mathrm{kg} . \mathrm{h}$. If the former value can be taken to be close to the standard rate of Liza macrolepis it can be said then, that most of the metabolic rates of the fish determined at various swimming velocities, as well as the extrapolated value of $150 \mathrm{mg} . \mathrm{kg} . \mathrm{h}$, are displaced upward due to the excitability (the 'ecologically moulded behaviour') of the fish (BRETT and SUTHERRLAND, 1965; WOHLSCHLAG and CAMERON, 1967). Whether the value of $100 \mathrm{mg} . \mathrm{kg} . \mathrm{h}(150-50)$, for example, can be taken as a measure of excitability of 
the fish, is yet to be confirmed, especially since it is known that even an apparently quiet fish can be excited to respire at any level up to almost the highest possible (active) metabolic rate (FRY, 1967). It is of interest that similar values, estimated from the data already available for goldfish and rainbow trout (KUTTY, 1966), can be made out as 40 (at $20^{\circ} \mathrm{C}$ ) and 120 (at $15^{\circ} \mathrm{C}$ ) mg.kg.h, respectively. Goldfish is comparatively a tamer fish, and perhaps the difference in excitability of the 2 species is, in most cases, reflected in oxygen consumption determined at the low swimming speeds. Separation of factors causing excitement from other energy-consuming biological processes in the whole individual will indeed be of much value for a clearer interpretation of information obtained on oxygen consumption in fish.

\section{Summary}

1. Oxygen consumption in the mullet Liza macrolepis (Sмгтн) of about $10 \mathrm{~cm}$ length, acclimated to and tested in fresh water at $29^{\circ} \mathrm{C}$, increased from a value of about $200 \mathrm{mg} . \mathrm{kg} . \mathrm{h}$ at a swimming velocity of $10 \mathrm{~cm} / \mathrm{sec}$ to $350 \mathrm{mg} . \mathrm{kg} . \mathrm{h}$ at $22 \mathrm{~cm} / \mathrm{sec}$. The oxygen consumption at the lowest swimming effort tested $(5 \mathrm{~cm} / \mathrm{sec})$ remained high at $350 \mathrm{mg} . \mathrm{kg} . \mathrm{h}$.

2. Tests on Liza macrolepis tagged with a plastic opercular tag showed that the trend, and the level of metabolic rates at various swimming speeds, were similar to those for the untagged fish. It appears that the tag does not cause any serious adverse effect in the respiration and swimming of the fish tested.

3. Routine metabolic rate of Liza macrolepis ranged between 85 and $551 \mathrm{mg} . \mathrm{kg} \cdot \mathrm{h}$ (mean $=260 \mathrm{mg}$. kg.h.).

4. Oxygen consumption at the lower swimming effort levels is high, possibly due to excitement and inefficient swimming as suggested by earlier workers. The interpretation of the elevation of the line drawn through the mean rates of metabolism at various swimming speeds, in relation to the standard metabolic rate, may be of significance with reference to the quantitative expression of excitability of different species.

Acknowledgments. The present study arose from my work in Professor F. E. J. FRY's Laboratory at the University of Toronto, Canada. I am grateful to the Director, Central Marine Fisheries Research Institute, Mandapam Camp, India, for providing facilities for this work, and to $\mathrm{Mr}$. G. MURUGAPOOPATHY for help in condueting the experiments. The opercular tags used in this study were obtained for test purposes from Dr. C. J. KerswILL, Biological Station of the Fisheries Research Board of Canada, St. Andrews, N. B. Canada by Dr. M. S. PrabHU. I am grateful to Professors F. E. J. Fruy and S. Krishnaswaury, and to Dr. S. V. Job for their comments on my manuscript.

\section{Literature cited}

Alverson, D. L. and H. H. ChEroweth: Experimental testing of fish tags on albacore in a water tunnel. Comml Fish. Rev. 13, 1-17 (1951).
Bantrimide, R.: Problems in fish locomotion. Symp. zool. Soc. Lond. 5, 13-32 (1961).

BeAmISH, F'. W. H.: Influence of starvation on standard and routine oxygen consumption. Trans. Am. Fish. Soc. 93, 103-107 (1964).

- and L. M. DICKIE: Metabolism and biological production in fish. Symposium on the 'Biological basis of freshwater fish productivity', Reading, U.K. 1966. (1966).

BRETT, J. R.: The energy required for swimming by young sockeye salmon with a comparison of the drag force on a dead fish. Trans. R. Soc. Can. (Sect. 1V) 1, 441-457 (1963).

- The respiratory metabolism and swimming performance of young sockeye salmon. J. Fish. Res. Bd Can. 21, 11831226 (1964).

- The swimming energetios of salmon. Scient. Am. 213, $80-85(1965)$.

- and D. B. SUTHERLAND: Respiratory metabolism of Pumpkin seed (Lepomis gibbosus) in relation to swimming speed. J. Fish. Res. Bd Can. 22, 405-409 (1965).

Clañer, D. W.: The effect of tagging with Petersen disc tags on the swimming ability of fingerling steelhead trout (Salmo gairdneri). J. Fish. Res. Bd Can. 20, 969-981 (1963).

Durve, V. S.: The effects of anaesthetics in the behaviour of mullet fingerlings. I. Effects of Tertiary butyl alcohol, chloral hydrate, chlorobutanol, sodium amytal, sodium barbital and urethane. J. mar. biol. Ass. India 8, 28-55 (1967).

FRY, F. E. J.: Aquatic respiration of fish. In: Physiology of fishes, Vol. 1, pp 1-53. Ed. by M. E. Brows. New York: Academic Press 1957.

- Responses of vertebrate poikilotherms to temperature. In: Thermobiology, pp 375-409. Ed. by A. H. Rose. London: Academic Press 1967.

- and J.S. HART: Cruising speed of goldfish in relation to water temperature. J. Fish. Res. Bd Can. 7, 109-175 (1948).

Joв, S. V.: The oxygen consumption of Salvelinus frontinalis. Publs Ont. Fish. Res. Lab. 73, 1-39 (1955).

- The routine active oxygen consumption of the milk fish. Proc. Indian. Acad. Sci. 45 (B), 302-313 (1957).

KUTтr, M. N.: Some studies on the respiratory quotient in goldfish and rainbow trout. Ph. D. Thesis, Univ. Toronto, Toronto, Ontario, vii + 104 p. (National Library of Canada, Canadian theses on microfilm, No. 646) 1966.

- Oxygen consumption in the prawns, Penaeus indicus and Penaeus semisulcatus. In: $\mathrm{FAO}$ World Conference on the biology of shrimps and prawns. Mexico, June, 1967.

- Respiratory quotients in goldfish and rainbow trout. J. Fish. Res. Bd Can. 25, 1689-1728 (1968).

MuIR, B. S., C. J. NeLsor and K. W. Bridges: A method of measuring swimming speed in $\mathrm{O}_{2}$ consumption studies on the Aholehole, Kuhlia sandivicensis. Trans. Am. Fish. Soc. 94, 378-383 (1965).

SMTT, H.: Some experiments on the oxygen consumption of goldfish (Carassius auratus L.) in relation to swimming speed. Can. J. Zool. 43, 623--633 (1965).

WoHLSCHLAG, D. E. : Differences in metabolic rates of migratory and resident freshwater forms of an Arctic whitefish. Eicology 38, 502-510 (1957).

- Antarctic fish growth and metabolic differences related to sex. Ecology 43, 589-597 (1962).

- and J. N. CAMinion: Assessment of a low level stress on the respiratory metabolism of the pinfish (Lagodon rhomboides). Contr. mar. Sci. 12, 160-171 (1967).

Author's address: Reader M. N. KणтrY

Department of Biological Sciences

Madurai University

Madurai-2, India 